Population Studies

A Journal of Demography

\title{
Health outcomes of only children across the life course: An investigation using Swedish register data
}

\section{Katherine Keenan, Kieron Barclay \& Alice Goisis}

To cite this article: Katherine Keenan, Kieron Barclay \& Alice Goisis (2022): Health outcomes of only children across the life course: An investigation using Swedish register data, Population Studies, DOI: 10.1080/00324728.2021.2020886

To link to this article: https://doi.org/10.1080/00324728.2021.2020886
(c) 2022 The Author(s). Published by Informa UK Limited, trading as Taylor \& Francis Group

\section{$+$}

View supplementary material $₫$

册 Published online: 01 Feb 2022.

Submit your article to this journal $\pi$

LIII Article views: 207

Q View related articles $₫$

View Crossmark data $\asymp$ 


\title{
Health outcomes of only children across the life course: An investigation using Swedish register data
}

\author{
Katherine Keenan ${ }^{1}$, Kieron Barclay ${ }^{2,3,4}$ and Alice Goisis ${ }^{2,5}$ \\ ${ }^{1}$ University of St Andrews, ${ }^{2}$ Max Planck Institute for Demographic Research, ${ }^{3}$ Stockholm University, \\ ${ }^{4}$ Swedish Collegium for Advanced Study, ${ }^{5}$ University College London
}

\begin{abstract}
Only children (with no full biological siblings) are a growing subgroup in many high-income settings. Previous studies have largely focused on the short-term developmental outcomes of only children, but there is limited evidence on their health outcomes. Using Swedish population register data for cohorts born 1940-75, we compare the health of only children with that of children from multi-child sibling groups, taking into account birth order, family size, and presence of half-siblings. Only children showed lower height and fitness scores, were more likely to be overweight/obese in late adolescence, and experienced higher later-life mortality than those with one or two siblings. However, only children without half-siblings were consistently healthier than those with half-siblings, suggesting that parental disruption confers additional disadvantages. The health disadvantage was attenuated but not fully explained by adjustment for parental characteristics and after using within-family maternal cousin comparison designs.
\end{abstract}

Supplementary material for this article is available at: http://dx.doi.org/10.1080/00324728.2021.2020886

Keywords: life course; health; mortality; family size; only child; sibling; family complexity; Sweden; register data

[Submitted February 2020; Final version accepted August 2021]

\section{Introduction}

The consequences of sibship constellations for health across the life course are significant, and previous research has demonstrated that later-born children (i.e. those of higher birth order) and those with more siblings experience poorer health compared with other types of children (Barclay and Kolk 2015; Baranowska-Rataj et al. 2017). However, the health outcomes of only children (i.e. those with no biological siblings) have so far been underexplored. While scholars have long been interested in how only children may be different to those with siblings, the majority of the literature has focused on shortterm developmental and cognitive outcomes in early life or adolescence (Blake 1981; Falbo and Polit 1986; Mancillas 2006; Falbo 2012), rather than on health. The question of health deserves further attention, given that only children constitute a substantial subgroup of all sibship groups in highincome, low-fertility settings (Frejka et al. 2008;
Präg et al. 2020). Increasing levels of childbearing postponement, occurring as part of the Second Demographic Transition (Lesthaeghe 2010), mean that this share might be expected to increase in future. Alongside this, the growing prevalence of multi-partner fertility has increased the proportion of (biologically) only children with half-siblings (Thomson 2014). Therefore, any investigation of only children should distinguish between only children with and without half-siblings.

This study uses Swedish population register data to investigate the health outcomes of only children relative to children in other types of sibling groups at various stages of the life course, from late adolescence (ages 17-20) to age 50 and over. We consider a range of anthropometric outcomes measured in late adolescence (height, weight, and physical fitness) and also adult mortality, both of which have shown strong associations with birth order and family size in other studies (Myrskylä et al. 2013; Barclay and Myrskylä 2014; Barclay and Kolk 2015; 
Baranowska-Rataj et al. 2017). We make two particularly innovative contributions to the literature. First, throughout the analyses, we compare only children with children from other sibship types, taking into account birth order, family size, and presence of half-siblings in order to account for family complexity and how this might result in different health outcomes between only children and children raised in other types of sibling groups. Second, we pay particular attention to the role of parental selectivity, which may play an important role in explaining the health outcomes of only children (Blake 1981; Mancillas 2006; Falbo 2012). It is likely that where one-child families are non-normative, as in the case of Sweden, their parents may be selected to a greater extent on a number of social and health factors, which may help to explain any differences in health outcomes for only children compared with those with full and half-siblings (Blake 1981). To account for the role of selection, we adjust for parental socio-demographic and socio-economic characteristics, and for the first time in the literature on only children, we use within-family maternal cousin comparison designs to adjust for all time-invariant factors that remain constant within the extended family.

\section{Background}

\section{The demographic context of only children}

Across high-income countries, the proportion of women having one child diverged over the twentieth century, increasing in some countries of Southern, Eastern, and Central Europe and remaining relatively low and stable in Nordic countries, such as Sweden (Präg et al. 2020). The majority of Swedish children born 1940-75 (our study cohorts) had one or two full biological siblings (Figure 1) and being an only child was a minority experience. Among those born before 1945, the proportion of children from one-child sibling groups was 19 per cent; this subsequently declined to a low of 14 per cent in the 1960 cohort, followed by a slight increase up to the 1975 cohort, before settling at around 1415 per cent for children born 1980-95.

Selectivity is a key potential explanation for differences in health outcomes between only children and children with siblings. Generally, cross-national data show that parents of small families (one or two children) have more years of education compared with parents of larger families (Choi et al. 2020), which corroborates findings from the United States (US) (Blake 1989), the Netherlands (Bras et al. 2010), and the UK (de La Rochebrochard and Joshi 2013). However, a recent study addressing only children's educational outcomes suggested that in contexts where only children are rarer (such as Sweden), they are more likely to be negatively socio-economically selected (Choi and Monden 2017).

Parents of only children likely include a subset whose fertility desires were interrupted due to partnership disruption or health reasons, which might also negatively influence child outcomes. Only children are more likely to live in one-parent households, both in the US (Falbo and Polit 1986; Datar 2017) and the UK (Sheppard and Monden 2020). In Sweden only children are more likely to be the offspring of divorced or separated parents (Andersson 1997), a situation which is itself

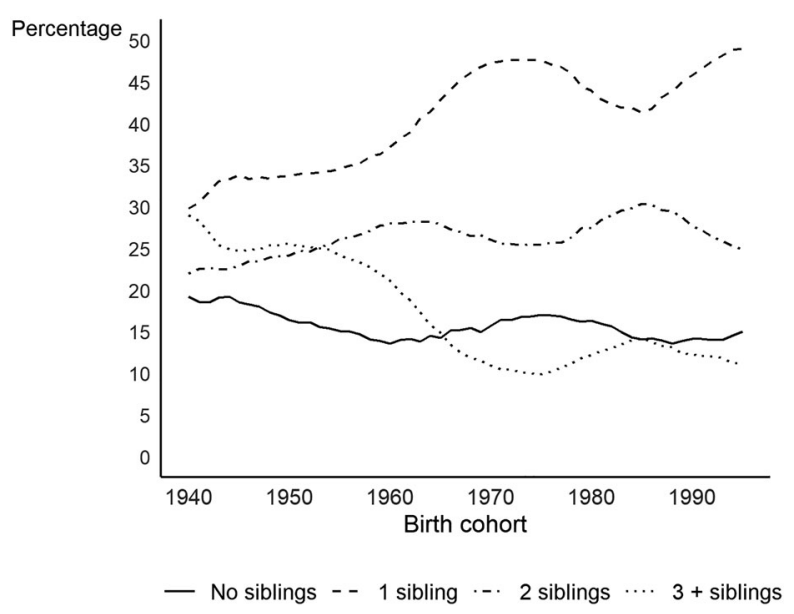

Figure 1 Percentage of children by biological sibling group size in the family of origin: men and women born in Sweden, 1940-95

Note: Figures based on birth records of children with a shared biological mother and father.

Source: Authors' calculations from Swedish population register data. 
associated with a range of negative offspring social and health outcomes (Amato and Keith 1991; McLanahan et al. 2013; Turunen 2014; Goisis et al. 2019). Separation and divorce rates in Sweden are relatively high, as is the repartnering rate, and this contributes to increases in the proportion of children with half-siblings (Thomson 2014; Thomson et al. 2020). Among the 1940 cohort, just 8 per cent of children had half-siblings, but this increased to nearly 27 per cent in the 1975 cohort. Therefore, a growing share of children who are the only child of their mother-father pairing also have half-siblings. On one hand, they could (conditional on shared residence) experience some of the (possibly) positive effects of having siblings. On the other hand, parental separation and family disruption, which are associated with worse outcomes, could offset the positive effects. Indeed, in the Swedish context, children with half-siblings experience poorer educational outcomes (Turunen 2014). This underlines how only children are an increasingly heterogeneous group, something which has not usually been accounted for in previous studies but which we are able to explore, given the richness of our study data.

Another plausible selection factor affecting both parity progression and child outcomes is poorer parental health. There is evidence from Sweden, Norway, and Finland that mortality rates are higher among parents of only one child than among those of parity two or three (Grundy and Kravdal 2007; Barclay, Keenan, et al. 2016; Einiö et al. 2016). The pattern is likely explained by a combination of biosocial behaviours/influences and partnership patterns. The relationship between poor health and lower fertility is also well established, and this may operate through social mechanisms (e.g. partnership patterns) or biological mechanisms (e.g. reduced fecundity). For example, physiological health factors, such as obesity (Ramlau-Hansen et al. 2007; Barclay and Kolk 2020) and smoking (Homan et al. 2007), are associated with subfecundity in men and women.

\section{Health outcomes of only children: Theory and empirical research}

Academic interest in only children dates back over a century. Early studies tended to stigmatize only children. For example, the influential psychologist G. Stanley Hall is famously quoted as saying that 'being an only child is a disease in itself' (cited in Fenton [1928]), and his contemporary Alfred Adler considered only children spoilt and negatively socially selected, with neurotic, mentally unstable parents (Adler 1930). Most of the only child research over the last 50 years has been concerned with shortterm intellectual, psychological, or social development outcomes, rather than medium- or long-term health. Overall, this body of research has repudiated the negative stereotype of only children. Several reviews and meta-analyses have suggested that only children do not have intellectual or developmental disadvantages in early life; indeed, in some domains they seem to do better than children with siblings (Falbo and Polit 1986; Polit and Falbo 1987; Falbo 2012). An educational and social advantage for only children has also been found in studies from China, where the one-child policy may be considered an exogenous shock on family size (Poston and Falbo 1990; Chen and Goldsmith 1991; Falbo and Poston 1993; Falbo 2012). We do not review the non-health literature in detail here (others have done this comprehensively, e.g. Mancillas [2006]); instead we focus on possible mechanisms for health outcomes, bringing in relevant theories and studies where necessary.

Sibship size, only children, and health outcomes. A collection of recent studies using within-family comparisons have demonstrated substantial differences in life course health outcomes by family size and birth order (Barclay and Myrskylä 2014; Barclay and Kolk 2015; Öberg 2015; Barclay, Myrskylä, et al. 2016; Black et al. 2016; BaranowskaRataj et al. 2017). The relationship between health and birth order is mixed: on one hand, there is consistent evidence that firstborn or earlier-born children (i.e. those of lower birth order) are taller, physically fitter and experience lower mortality (Myrskylä et al. 2013; Barclay and Myrskylä 2014; Öberg 2015; Black et al. 2016; Stradford et al. 2017), but on the other hand they are more likely to be obese and to have high blood pressure (Jelenkovic et al. 2013; Derraik et al. 2015; Black et al. 2016). Within-family designs have become a popular way of attempting to control potential confounding effects of parental selection when investigating child outcomes, but one weakness is that the design, by necessity, excludes only children. Therefore, empirical research on only children's health outcomes is sparse and under-theorized.

The resource dilution hypothesis has been posited as an important theory explaining the health and developmental advantages accruing to earlier-born children (Blake 1981; Downey 1995, 2001), and it may help to explain only child outcomes too. This theory suggests that as earlier-born children spend 
a period of their lives with the exclusive attention and resources of their parents, they reap a developmental advantage relative to their younger siblings, who always share resources with other siblings. Similarly, economic theories that describe the 'trade-off' between child quality and quantity also suggest that earlier-born children or those with no siblings benefit from the undivided economic and time resources of their parents (Becker and Lewis 1973). Perspectives from evolutionary demography highlight the possibility of strategic fertility limitation to accrue health and economic advantages and transmit these intergenerationally (Lawson and Mace 2011). The educational and intellectual advantages observed in childhood among only children relative to children with siblings or later-born children (Gee 1992; Falbo 2012; Barclay 2014; Black et al. 2016) may mediate short- and long-term health advantages. An alternative explanation (discussed earlier) is that larger families are negatively socially selected, and this contributes to poorer outcomes through a combination of genetic and environmental influences, although it should be noted that the sibship-health associations usually persist when using within-family comparisons (Barclay and Myrskylä 2014; Barclay 2015; Barclay and Kolk 2015; Black et al. 2016). In the case of only children's health, it is unclear how much negative selection offsets the benefits of exclusive parental attention and resources.

Height and sibship size. Height is an important predictor of future health and mortality (Engeland et al. 2003; Stulp and Barrett 2016) and is itself a result of a combination of genetic and environmental influences. Negative associations between family size and height have been reported in various historical populations, including in Swedish cohorts born between the 1820s and 1960s (Cernerud 1993; Öberg 2015), in Dutch conscripts born 1944-47 (Stradford et al. 2017), and in UK cohorts born in the 1890s (Bailey et al. 2016) and 1930s (Hatton and Martin 2009). A complementary investigation into birth order effects using cohorts of Swedish men born between the 1950s and 1980s (Myrskylä et al. 2013) found that earlier-born children were on average taller but that the association had weakened over time, a finding also reported by Öberg (2015) and attributed to secular improvements in nutrition and healthcare. It seems plausible for historical populations that resource dilution may also help to explain sibling-height associations (Öberg 2015, 2017; Riswick and Engelen 2018), because competition and scarcities within families can affect nutrition and access to healthcare, contributing to reduced growth and development.

The evidence on only children's height is rather thin. In cohorts born in southern Sweden in 18211950, (Öberg 2015, p. 44) reported that 'men who were the only children in the family were considerably shorter than others in all periods'. A study of Dutch conscripts born in the 1940s reported shorter heights for only children (Stradford et al. 2017). Resource dilution does not contribute to explaining only children's apparently shorter stature and is a less relevant explanation for contemporary, high-income populations (Stulp and Barrett 2016). How is parental height related to fertility, and could heritability help to explain these patterns? The evidence on height and fertility from developed countries suggests that the relationship is curvilinear: that fertility is lowest among both very short and very tall people (Stulp and Barrett 2016). A recent analysis of Swedish men confirmed this, showing that shorter men had fewer children (Barclay and Kolk 2020). Analysis of parity progression stratified by marital status indicated that this was related not to lower fecundity but to the higher propensity of shorter and taller men to remain unmarried, which for shorter men is possibly linked to lower desirability as a mate (Barclay and Kolk 2020). This suggests that only children's lower height could be explained by lower paternal height affecting fertility or partnership patterns. The relationship between height and fertility is more mixed for females, varying by context (Sear 2006). Given that there is very limited evidence on only children's height from contemporary cohorts, it is unclear whether they will approximate the pattern of firstborns and those in smaller families and be of taller stature (supporting the resource dilution hypothesis) or will be shorter than those with siblings, due to either genetic traits (e.g. having shorter parents with lower fertility) or possible negative environmental factors (e.g. resource scarcity related to parental disruption) that may impair growth.

Body weight and sibship size. There is substantial evidence that only children are more likely to be overweight/obese, and more so than firstborns (Meller et al. 2018; Park and Cormier 2018). Selectivity may play a less important role for obesity than for the other outcomes in our study, because evidence comes from diverse settings where only children might be differentially selected. Such settings include: low-fertility contexts, such as Japan 
(Wang et al. 2007); regions where two- or three-child families are normative, such as the US (Mosli et al. 2016; Datar 2017) and Northern Europe (Haugaard et al. 2013; Jelenkovic et al. 2013); and also China, where the one-child policy likely reduced the social selectivity of only children (Cheng 2013; Li et al. 2017; Min et al. 2017). Evidence from sibling comparisons also reveals that firstborns are more likely to be overweight than later-born siblings (Jelenkovic et al. 2013). Like firstborns, only children tend to be smaller at birth than later-born children, and this can result in catch-up patterns of growth, which are related to obesity and some indicators of cardiovascular disease (Ong et al. 2000; Monteiro and Victora 2005; Wells et al. 2011).

Child health behaviours may also contribute to the association. Studies have reported that parents of only children are more attendant to their children's feeding compared with other parents (Mosli et al. 2015), and only children are more likely to exhibit 'obesogenic' behaviours, such as lower physical activity and more screen time (Bagley et al. 2006; Hallal et al. 2006; Sisson et al. 2014), than those with siblings. Overweight is also associated with lower fertility and subfecundity (Ramlau-Hansen et al. 2007; Frisco and Weden 2013; Barclay and Kolk 2020), so it is plausible that parental genetic factors and/or poor health behaviours contribute to these patterns. There is limited evidence on whether these only child disparities in body mass index (BMI) persist beyond childhood.

Physical fitness and sibship size. Physical fitness reflects cardio-respiratory health and muscular strength, and differences in physical fitness are likely driven by similar mechanisms to those affecting height, for example resource dilution. The evidence on physical fitness and sibship size is sparse but suggests similar negative associations as for height (i.e. that earlier-born children are fitter; Barclay and Myrskylä 2014). However, that study did not explore only children's fitness and, as only children are more likely to be obese, physical fitness may follow the same pattern as weight. To our knowledge the only study to explore only children's fitness was from Portugal (where only children are relatively common), and it found that only children aged 5-17 years performed worse on a battery of tests measuring cardiovascular and muscular abilities (Rodrigues et al. 2020) than those with siblings. Lower levels of physical fitness are also associated with lower fertility (Barclay and Kolk 2020), suggesting potential transmission of lower fitness in only-child families, either through genetic mechanisms or factors such as health behaviours.

Mortality and sibship size. Findings from a recent Swedish study suggested that only children born from 1930 to 1960 experienced higher mortality rates than children with siblings, even after socioeconomic factors were accounted for (BaranowskaRataj et al. 2017). As with height and fitness outcomes, this contradicts the consistently observed positive relationship between birth order and mortality (Barclay and Kolk 2015). We might speculate that the patterns we discussed earlier of shorter stature, lower physical fitness, and higher weight in childhood and adolescence will cumulate to result in premature mortality for only children. However, given that there is sparse evidence on the adult health of only children, it is not certain that the health disadvantages observed in childhood persist through life. Mortality patterns could also be mediated by poorer non-health life course outcomes. Only children are more likely to divorce or separate (Gee 1992; Diekmann and Engelhardt 1999; Dronkers and Härkönen 2008; Bobbitt-Zeher et al. 2016) and, if they have half-siblings, to experience multi-partner fertility (Lappegård and Thomson 2018). Only children are also more likely to be childless or have one child themselves (Kolk 2014), which in the Swedish context is associated with higher mortality (Barclay, Keenan, et al. 2016).

To summarize this subsection, the evidence on the health of only children is sparse and comes from a range of differing contexts and cohorts, where only children might be more or less selected. However, the literature generally suggests health disadvantages for only children relative to those with siblings, with the strongest evidence for body weight. Given the strong two-child norm in Sweden, only children are a minority group, hence we might expect them to be negatively socially selected on parents' health and social characteristics and more likely to come from disrupted families. In this respect, it is vital to disaggregate only children with and without half-siblings in order to disentangle the role of family structure from other mechanisms.

\section{Data and methods}

\section{Data}

In this study we use Swedish population register data to examine how sibling group size, in particular only 
child status, in the family of origin is related to health in early adulthood and mortality in later life. Each individual in Sweden is given a unique personal identification number (PIN) that is universally used for administrative purposes. In this study, we rely on the Swedish multi-generation register, which allows us to link individuals to their parents and siblings. We examine the subset of sibling groups where all the children were born in Sweden to maximize the accuracy of the parent-child sibling linkages. In our analysis we also distinguish between children who were raised in blended families and those who were not. Consequently, we exclude any children who are missing information on either the maternal or paternal linkage, but this is less than 1 per cent of children in the birth cohorts that we study. We also exclude children in sibling groups with multiple births, such as twins, as birth order is an important component of our analysis and multiple births confuse the assignment of birth order.

We examine the relationship between sibling group size and four outcome variables: height, physical fitness, being overweight/obese, and mortality. Apart from mortality, information on all outcome variables is drawn from the Swedish military conscription register. In Sweden, men in the cohorts for whom we have data were universally required to report for military conscription tests between ages 17 and 20 to determine their physical and psychological suitability for military service. We use data on height, physical fitness, and BMI for cohorts born in 1965-75. Since only men were required to report for conscription tests in Sweden, data on these measures are not available for women. However, the measures of sibling group size and other characteristics of the sibling group are based on the whole sibling group, including brothers and sisters.
The other main register that we use is the Swedish cause of death register (mortality register), which contains detailed information on all deaths in Sweden between 1960 and 2017. In our mortality analyses we include both men and women. Although our access to the Swedish mortality register includes data for the period 1960-2017, the multi-generational registers that allow family members to be linked to one another are incomplete before the 1990s (Statistika Centralbyrån 2017). For this reason, we start our analysis of all-cause mortality at age 50. To be included in our analytical sample individuals must have survived to age 50 . We also exclude individuals who have ever emigrated from Sweden before age 50. Table 1 details how we reach our final analytical samples for the conscription data analysis ( $n=532,659$ and $n=182,870$ for the two sets of models) and the mortality analysis $(n=1,910,086)$.

\section{Sibling group size, birth order, and blended families}

The key explanatory variable in our study is sibling group size. Although we focus on only children, we compare only children with children raised in sibling groups of two, three, or four or more children, rather than assuming that multi-child sibling groups are homogenous. We also explicitly model birth order as part of our sibling group size variable, to test whether only children's outcomes are similar to those of firstborn children in multi-child sibling groups, given that both groups spend a period of time in early childhood with the exclusive attention of their parents. Furthermore, since later-born children generally do worse than firstborns, later-born siblings lower the average achievement in multi-

Table 1 Sample exclusion process for this study

\begin{tabular}{lcc}
\hline & $N$ included & $N$ excluded at each stage \\
\hline Analysis of male health outcomes at ages 17-20 & - \\
Total men born in Sweden 1965-75 & 634,403 & 7,433 \\
ID for both parents & 626,970 & 15,360 \\
No multiple births & 611,610 & 78,951 \\
No missing values on conscription variables & 532,659 & 349,789 \\
Not missing grandmother ID and has at least one male maternal cousin & 182,870 & - \\
Analysis of mortality after age 50 & & 159,648 \\
Total men and women born in Sweden 1940-60 & $2,305,911$ & 71,437 \\
ID for both parents & $2,146,263$ & 135,624 \\
No multiple births & $2,074,826$ & 29,116 \\
Did not emigrate or die before age 50 & $1,939,202$ & $1,910,086$ \\
No missing values on key covariates & \\
\hline
\end{tabular}

Source: Authors' calculations from Swedish population register (analysis of male health outcomes) and mortality register data (analysis of mortality). 
child sibling groups. This means that a detailed consideration of the interplay of family size and birth order is essential for comparing the outcomes of only children with those of children in larger families. Our key explanatory variable contains the following nine categories:

- Only child

- Firstborn in a two-child sibling group

- Second-born child in a two-child sibling group

- Firstborn in a three-child sibling group

- Second-born child in a three-child sibling group

- Third-born child in a three-child sibling group

- Firstborn in a sibling group with four or more children

- Middle-born child in a sibling group with four or more children

- Last-born child in a sibling group with four or more children

An individual designated as an only child is the only biological child of both the mother and the father. To take account of complex families, our main analyses always feature an interaction between our nine-category variable on birth order and family size with a binary variable for whether or not the index person has any half-siblings on either the maternal or paternal side. Hence, our analyses include 18 categories, reflecting the interaction between sibship size, birth order, and presence of any half-siblings. We distinguish between two categories of only children in our analyses: 'nonblended' only children (children who are the only child of their unique mother-father pairing and have no half-siblings) and 'blended' only children (children who are the only child of their unique mother-father pairing but have half-siblings from either the maternal side, the paternal side, or both).

\section{Outcome variables}

Height (men). Height, measured in centimetres, is standardized (using $z$-scores) for our analyses.

Physical fitness (men). Our measure for physical fitness is based on a measure of maximal working capacity, measured in watts. Maximal working capacity (MWC) - measured as the maximum resistance attained in watts when riding on a stationary bike for 5-10 minutes (one of the most effective ways of measuring aerobic fitness) -is closely related to maximal oxygen uptake $\left(\mathrm{VO}_{2}\right.$ max $)$, also known as maximal aerobic capacity. The correlation between these two variables has been reported to be approximately 0.9 (Patton et al. 1982). The MWC variable is an important predictor of mortality in adulthood among men (Sandvik et al. 1993). Because a measure of MWC in watts is not intuitively easy to interpret, we standardize this outcome measure using $z$-scores.

BMI (men). We calculate BMI as mass (in kilograms) divided by the square of height (in metres) at the time of the military conscription test. Using the standard cut-off points, we focus on whether our index persons were overweight/obese at the time of the test, indicated by whether they had a BMI of 25 or greater.

Mortality (men and women). We study mortality in the period 1990-2017 for Swedish men and women born in 1940-60. We focus on all-cause mortality from age 50. That means we study the 1940 birth cohort from age 50 in 1990 through to age 77 in 2017. For the 1960 cohort it means that we follow them from age 50 to age 57 .

\section{Covariates}

We include in our models a number of control variables that previous studies have shown to covary with both our explanatory variable and our outcome variables. In the military conscription analyses on height, physical fitness, and BMI, we include the birth year of the index person (1965, 1966 ... 1975), which is associated with family size as well as with secular trends in our health measures. We control for both maternal age $(15-19,20-24, \ldots$ $35-39,40+)$ and paternal age $(15-19,20-24, \ldots 40-$ $44,45+)$ at the time of the index person's birth, as age at childbearing covaries with family size and birth order as well as with health outcomes (Barclay and Myrskylä 2016). We also use information on maternal and paternal educational attainment, with eight categories: primary $(<9$ years $)$, primary (9 years), secondary (10-11 years), secondary (12 years), tertiary (13-15 years), tertiary but not including postgraduate qualifications (15+ years), postgraduate qualifications (approximately 16-20 years), and 'missing'.

To adjust further for socio-economic conditions in the family of origin, we use the mother's and father's socio-economic status (as reported in the 1960 Census), which is based on the Erikson, Goldthorpe, 
and Portocarero (EGP) occupational class scheme (Erikson et al. 1979) with 12 categories. Further controls include a binary variable for whether the index person's parents had divorced by the time the index person reached age 16 and binary variables for whether their mother or father had died before they reached age 17 .

In the mortality analyses we also control for variables capturing important socio-demographic and socio-economic factors during adulthood for our index persons. These include whether the index person's mother or father had died before age 50 , the index person's marital status at age 50 (never married, married, divorced, widowed), their own educational attainment (same categories as used for the educational attainment of parents), their own socio-economic status (taken from the 1990 Census), and the number of children that they had by age $50(0,1, \ldots 6+)$. All these variables have been shown to covary with family size as well as with health outcomes (Cherlin et al. 1998; Weitoft et al. 2003; Torssander and Erikson 2010; Rostila and Saarela 2011; Myrskylä et al. 2014; Barclay, Keenan, et al. 2016).

\section{Statistical analyses: Military conscription data}

To study the relationship between sibling group size in the family of origin and our various health outcomes derived from the military conscription register, we use ordinary least squares regression, as well as linear regression with cousin fixed effects. Our outcome variables for physical fitness and height are continuous, but we analyse being overweight/obese as a binary variable. For the analysis of being overweight/obese, we use linear regression in the form of linear probability models with robust HuberWhite standard errors (Stock and Watson 2008).

The fixed effects are applied to the maternal cousin group (cousins who share the same maternal grandmother). The model identification is by comparing health results within a maternal cousin group where one cousin is an only child and the other has a different sibship constellation. Maternal cousin groups where both are only children do not contribute to the estimates due to the lack of variation. The use of maternal cousin fixed effects implicitly adjusts for all factors that are shared within the maternal cousin group, such as the size of the parental sibling group, grandparental resources (e.g. wealth), and other resources shared across the extended kin group. These may include material assets, such as shared wealth (e.g. a shared vacation home), and also symbolic aspects, such as a shared surname or a common family history and identity. The fixed effects approach also inherently adjusts for factors that are difficult to observe and measure, such as all elements of shared socio-economic background, to the extent that such factors are shared by cousins.

For each military conscription outcome variable (height, physical fitness, and overweight/obese), we estimate two models using the full population:

$$
\begin{aligned}
y= & \beta_{1} S G S B O \times \text { Blended }+\beta_{2} \text { BirthYear }+\alpha \\
& +\varepsilon \\
y= & \beta_{1} S G S B O \times \text { Blended }+\beta_{2} \text { BirthYear } \\
& +\beta_{3} X+\alpha+\varepsilon
\end{aligned}
$$

where $y$ is our outcome variable; $S G S B O \times$ Blended is our nine-category birth order and sibling group size variable interacted with a binary variable for whether or not the index person has any maternal or paternal half-siblings (yielding 18 discrete categories); BirthYear is a categorical variable for year of birth $(1965,1966, \ldots 1975)$; $\alpha$ is the constant; and $\varepsilon$ is the error term. In model (2) we introduce additional control variables indexed by $X$, a vector of family covariates described in the previous subsection.

For each of our three military conscription outcome variables, we also estimate a third model, using linear regression with maternal cousin fixed effects:

$$
\begin{aligned}
y_{i j}= & \beta_{1} S_{G S B O} \times \text { Blended }_{i j}+\beta_{2} \text { BirthYear }_{i j} \\
& +\beta_{3} X_{i j}+\delta_{j}+\varepsilon_{i j}
\end{aligned}
$$

where the subscripts $i$ and $j$ refer to sibling $i$ in cousin group $j$, and $\delta_{j}$ designates the maternal cousin fixed effect. Model (3) includes the same vector of control variables, $X$, that were included in model (2). The analytical sample for model (3) is based on cousin groups that share a maternal grandmother, hence we exclude individuals who are 'only cousins': an individual might have no maternal cousins, either because their mother was an only child or because all their aunts and uncles were childless. The sample is also restricted to those with at least one male cousin in order to obtain health outcomes from conscription data.

\section{Statistical analyses: Mortality}

To study mortality, we use survival analysis in the form of Cox proportional hazards regression 
(Cox 1972). The proportional hazards model is expressed as:

$$
h\left(t \mid X_{1, \ldots}, X_{k}\right)=h_{0}(t) \exp \left(\sum_{j=1}^{k} \beta_{j} X_{j}(t)\right)
$$

where $h\left(t \mid X_{1, \ldots,}, X_{k}\right)$ is the hazard rate for individuals with characteristics $X_{1, \ldots} X_{k}$ at time $\mathrm{t} ; h_{0}(t)$ is the baseline hazard at time $t$; and $\beta_{j}, j=1, \ldots k$ are the estimated coefficients. The timescale for the survival analysis is months. Because the failure event in our analysis is the death of the individual, the baseline hazard of our model, $h_{0}(t)$, is age. Individuals are censored on first migration out of Sweden, at death, or in 2017 (whichever comes first). We estimate the following three models:

$$
\begin{aligned}
\log h(t)= & \beta_{1} \text { SGSBO } \times \text { Blended }+\beta_{2} \text { Sex } \\
& +\beta_{3} \text { BirthYear } \\
\log h(t)= & \beta_{1} \text { SGSBO } \times \text { Blended }+\beta_{2} \text { Sex } \\
& +\beta_{3} \text { BirthYear }+\beta_{4} \text { Childhood } \\
\log h(t)= & \beta_{1} \text { SGSBO } \times \text { Blended }+\beta_{2} \text { Sex } \\
& +\beta_{3} \text { BirthYear }+\beta_{4} \text { Childhood } \\
& +\beta_{5} \text { Adulthood }
\end{aligned}
$$

where the outcome is the log hazard of mortality, $S G S B O \times$ Blended and BirthYear are as in the military conscription outcomes models, and Sex is selfexplanatory. Childhood is a vector of covariates that relate to the childhood environment, including categorical variables for maternal and paternal age at the time of birth of the index person, maternal and paternal educational attainment, and maternal and paternal socio-economic status (drawn from the 1960 Census). Finally, Adulthood is a vector of covariates related to important socio-demographic and socio-economic factors measured before age 50 , including binary variables for whether the index person's mother or father had died before age 50, their own marital status at age 50, their own educational attainment, their own socio-economic status (taken from the 1990 Census), and the number of children that they had by age $50(0,1$, ... 6+). Because the Swedish multi-generation register starts at 1932, we were unable to obtain information on maternal grandmothers for the older cohorts in the mortality sample; therefore, we did not run cousin fixed effects for the mortality outcome.

\section{Results}

Table 2 shows sample sizes and descriptive statistics for our two analysis samples, using the military conscription data (later-born cohorts) and the mortality register (earlier cohorts). Throughout the paper, non-blended only children are labelled OC, while the remaining eight birth order and sibling group category labels indicate birth order (First, F; Middle, M; and Last, L) and sibling group size. For example, a firstborn child from a three-child sibling group is labelled $\mathrm{F} / 3$.

There were proportionally more non-blended only children in the earlier cohorts born 1940-60 (11.9 per cent) compared with those born 1965-75 (6.1 per cent). This trend is largely consistent with the fullpopulation calculations in Figure 1, despite the military conscription data being restricted to men only. The share of all children that grew up in blended families was 14.1 per cent in the mortality sample and 24.7 per cent in the conscription sample, reflecting increased family complexity across cohorts. Similarly, the share of only children from blended families increased from 4.9 per cent in the mortality sample to 9.5 per cent in the conscription sample. The proportion of children with three or more siblings also declined in the later cohorts. In non-blended families (without half-siblings), mean fitness and height were generally lower among only children than those with siblings, except for those in sibling groups of four or more. Only children experienced the highest proportions overweight/obese and the highest mortality rates compared with most other groups, in both blended and non-blended families.

We also show a more detailed set of descriptive tables (Tables S1-S3 in the supplementary material), where all variables in our analysis are cross-tabulated by family size, birth order, and blended status. In the conscription data (Tables S1-S2) and mortality data (Table S3), non-blended only children were more likely to be born to older mothers than firstborn children with one sibling (indicating that age at first birth was higher for mothers with one child). In the conscription data, non-blended only children were more likely to be born to parents with lower levels of educational attainment than non-blended firstborns with siblings. In the mortality analyses sample, both blended and non-blended only children had the lowest mean number of children at age 50 compared with other groups, and the proportion unmarried by age 50 was also relatively high.

All models show results according to birth order and sibling group size, taking 'real' only children 
Table 2 Sample and study outcomes according to blended status, birth order, and sibling group size

\begin{tabular}{|c|c|c|c|c|c|c|c|c|c|c|}
\hline & \multirow[b]{3}{*}{$\begin{array}{l}\text { Birth order / } \\
\text { sibling group size }\end{array}$} & \multicolumn{5}{|c|}{ Military conscription sample (men born 1965-75) } & \multicolumn{4}{|c|}{$\begin{array}{l}\text { Mortality register sample (men and women born } \\
1940-60)\end{array}$} \\
\hline & & \multicolumn{2}{|c|}{ Sample size } & \multirow{2}{*}{$\begin{array}{c}\text { Height }(\mathrm{cm}) \\
\text { Mean }\end{array}$} & \multirow{2}{*}{$\begin{array}{c}\text { Fitness (watts) } \\
\text { Mean }\end{array}$} & \multirow{2}{*}{$\begin{array}{c}\text { Overweight/obese } \\
\text { Percentage }\end{array}$} & \multicolumn{2}{|c|}{ Sample size } & \multirow{2}{*}{$\begin{array}{l}\text { Mortality rate } \\
\qquad 10^{\wedge}-6\end{array}$} & \multirow{2}{*}{$\begin{array}{l}\text { Deaths } \\
\qquad N\end{array}$} \\
\hline & & $N$ & Percentage & & & & $N$ & Percentage & & \\
\hline \multirow[t]{9}{*}{ Non-blended (no half-siblings) } & $\mathrm{OC}$ & 32,700 & 6.1 & 179.4 & 296.5 & 14.3 & 227,188 & 11.9 & 2.0 & 29,202 \\
\hline & $F / 2$ & 100,462 & 18.9 & 179.7 & 303.7 & 11.1 & 296,614 & 15.5 & 1.6 & 30,068 \\
\hline & $\mathrm{L} / 2$ & 99,958 & 18.8 & 179.7 & 301.7 & 11.1 & 288,680 & 15.1 & 1.6 & 28,048 \\
\hline & $\mathrm{F} / 3$ & 38,386 & 7.2 & 179.5 & 303.0 & 10.6 & 147,994 & 7.7 & 1.6 & 14,640 \\
\hline & $\mathrm{M} / 3$ & 38,526 & 7.2 & 179.5 & 302.1 & 9.7 & 148,569 & 7.8 & 1.6 & 14,750 \\
\hline & $\mathrm{L} / 3$ & 41,612 & 7.8 & 179.5 & 298.1 & 12.3 & 126,541 & 6.6 & 1.6 & 11,219 \\
\hline & $\mathrm{F} / 4+$ & 9,432 & 1.8 & 179.0 & 297.1 & 11.6 & 82,147 & 4.3 & 1.9 & 9,810 \\
\hline & $\mathrm{M} / 4+$ & 23,837 & 4.5 & 178.6 & 292.6 & 10.9 & 247,955 & 13.0 & 1.8 & 28,485 \\
\hline & $\mathrm{L} / 4+$ & 16,345 & 3.1 & 179.0 & 290.6 & 13.8 & 75,508 & 4.0 & 1.6 & 6,496 \\
\hline \multirow[t]{9}{*}{ Blended (half-siblings present) } & $\mathrm{OC}$ & 50,699 & 9.5 & 179.0 & 293.7 & 13.8 & 93,767 & 4.9 & 2.0 & 10,007 \\
\hline & $\mathrm{F} / 2$ & 26,902 & 5.1 & 179.2 & 296.4 & 12.4 & 44,284 & 2.3 & 1.8 & 4,297 \\
\hline & $\mathrm{L} / 2$ & 25,436 & 4.8 & 179.1 & 294.1 & 11.8 & 35,203 & 1.8 & 1.8 & 3,289 \\
\hline & $\mathrm{F} / 3$ & 6,494 & 1.2 & 178.7 & 293.0 & 11.7 & 19,736 & 1.0 & 1.9 & 2,000 \\
\hline & $\mathrm{M} / 3$ & 6,493 & 1.2 & 178.9 & 291.0 & 10.8 & 17,110 & 0.9 & 1.8 & 1,634 \\
\hline & $\mathrm{L} / 3$ & 7,205 & 1.4 & 178.9 & 290.1 & 12.5 & 12,578 & 0.7 & 1.7 & 1,116 \\
\hline & $\mathrm{F} / 4+$ & 1,531 & 0.3 & 178.6 & 288.0 & 13.1 & 11,194 & 0.6 & 2.1 & 1,314 \\
\hline & $\mathrm{M} / 4+$ & 3,929 & 0.7 & 178.1 & 282.5 & 11.6 & 27,971 & 1.5 & 2.0 & 3,183 \\
\hline & $\mathrm{L} / 4+$ & 2,712 & 0.5 & 178.6 & 284.3 & 13.0 & 7,047 & 0.4 & 1.7 & 617 \\
\hline Total & & 532,659 & 100.0 & 179.4 & 298.7 & 11.7 & $1,910,086$ & 100.0 & 1.7 & 200,175 \\
\hline
\end{tabular}

Notes: 'Real' only children (i.e. those with no full or half-siblings) are labelled OC. The remaining eight birth order and sibling group category labels indicate birth order (First, F; Middle, M; and Last, L) and sibling group size. For example, a firstborn child from a three-child sibling group is labelled F/3.

Source: As for Table 1. 
(i.e. those with no full or half-siblings) as the reference category (OC). In Figures $2-5$ we distinguish between non-blended families with circles and blended families with squares. Full model results for all outcomes are shown in Tables S4-S7 in the supplementary material.

\section{Health outcomes in the military conscription register: Physical health at ages 17-20}

In Figures 2-4, model (1) - the baseline model-is adjusted only for birth year. Model (2), in addition to birth year, includes controls for parents' education and socio-economic status, parents' age at the time of the index person's birth, whether either parent had died before the child reached age 17, and whether the parents had divorced before the child reached age 16. Model (3) includes the same adjustments as model (2), but is run on a subsample described in the 'Data and methods' section and includes maternal cousin fixed effects, in other words, comparing sets of maternal cousins with one another.

Figure 2 shows the results for height $z$-scores for men aged 17-20. The estimates from model (1) show that among the non-blended families, height scores were significantly lower for only children than for children from sibling groups of two or three. On the other hand, these only children were substantially advantaged in height compared with those from sibling groups of four or more. Blended only children's height scores were significantly lower than those of non-blended only children. For all other birth order and sibling group categories, children from blended families were shorter. After adjustment for parental characteristics (model (2)), some of the differences between non-blended only children and those with full siblings diminished, and non-blended only children were disadvantaged only relative to non-blended firstborns from a two-child sibling group. In model (2), a monotonic decrease in height with birth order became more evident for two- and three-child sibling groups. In model (3) using cousin fixed effects, the differences between non-blended and blended children (including only children) were fully attenuated, but the confidence intervals were larger due to reduced sample size.

Figure 3 shows the results from linear probability models estimating the probability of being overweight/obese at ages 17-20. Model (1) shows that only children experienced significantly higher probabilities of being overweight/obese compared with

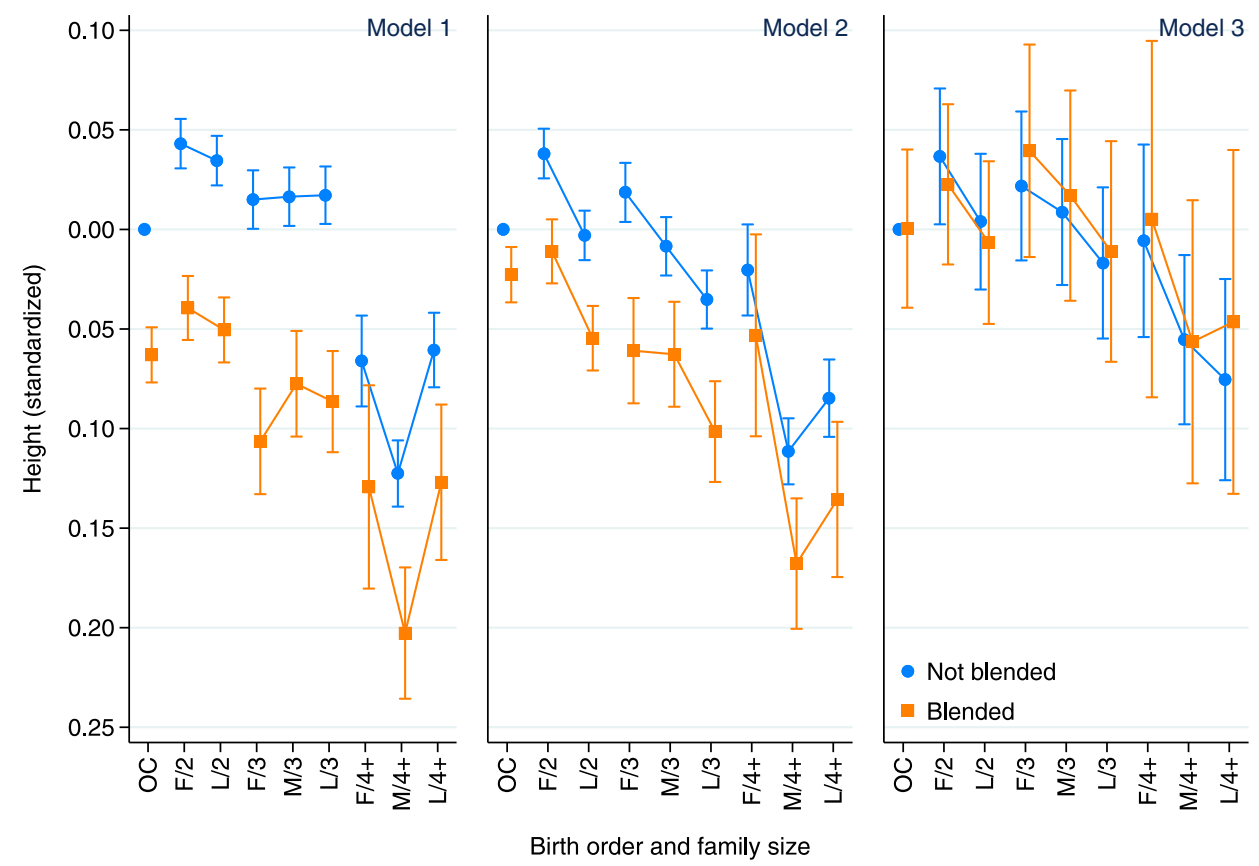

Figure 2 Results for standardized height scores among men aged 17-20, according to birth order, sibling group size, and blended family status: Swedish men born 1965-75

Notes: Model (1) is adjusted for birth year only; model (2) also controls for parental characteristics. Model (3) is run on a subsample and includes maternal cousin fixed effects. Non-blended only children (OC) are the reference category. The remaining eight birth order and sibling group category labels indicate birth order (First, F; Middle, M; and Last, L) and sibling group size. For example, a firstborn child from a three-child sibling group is labelled F/3.

Source: As for Figure 1. 


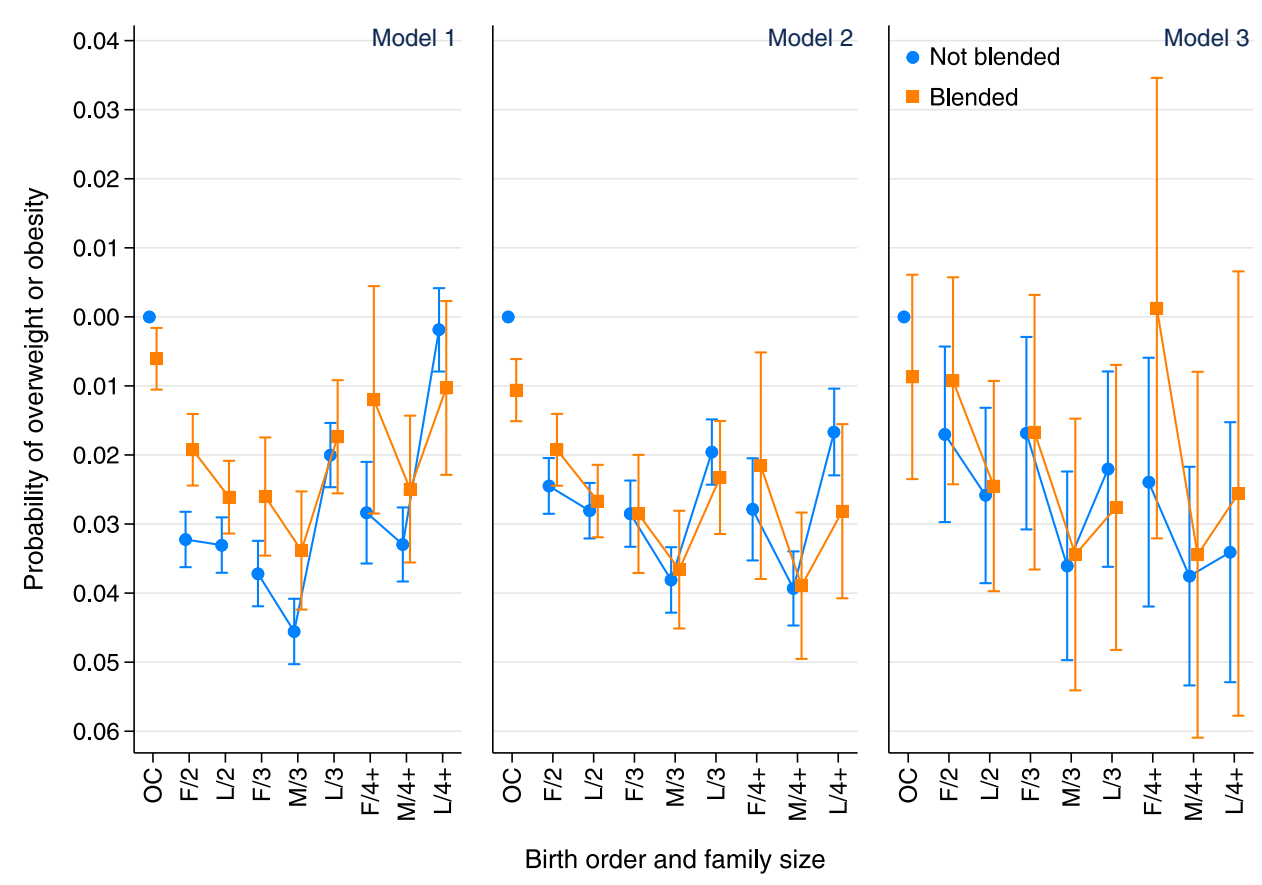

Figure 3 Results for overweight/obesity among men aged 17-20, according to birth order, sibling group size, and blended family status: Swedish men born 1965-75

Notes: Model (1) is adjusted for birth year only; model (2) also controls for parental characteristics. Model (3) is run on a subsample and includes maternal cousin fixed effects. Non-blended only children (OC) are the reference category. The remaining eight birth order and sibling group category labels indicate birth order (First, F; Middle, M; and Last, L) and sibling group size. For example, a firstborn child from a three-child sibling group is labelled F/3.

Source: As for Figure 1.

nearly every other sibship constellation, except for some children in larger sibling groups. In model (2), adjusted for parental characteristics, most differences between only children and those from larger sibling groups became smaller among non-blended families, while the gap between non-blended and blended only children widened. In this model, the difference between non-blended only children and non-blended children with one sibling was equivalent to two to three percentage points (a sizeable effect given that the sample average was 11.7 per cent overweight/obese) As for height, in models (1) and (2) non-blended only children did significantly worse in their health outcomes compared with blended only children. Model (3), additionally adjusted for maternal grandmother fixed effects, shows approximately the same pattern of only child disadvantage, with slightly smaller differences between non-blended and blended only children than in model (2).

Figure 4 displays the results for standardized fitness scores at ages 17-20. Model (1) shows that only children, regardless of their blended status, exhibited poorer fitness than non-blended children from two- and three-child sibling groups and similarly low fitness scores to non-blended children from sibling groups of four or more. In model (2), the disparity between only children and those with siblings was attenuated, but fitness scores among only children were still approximately 10 per cent of a standard deviation lower compared with firstborns with one sibling. In models (1) and (2), blended children showed significantly lower fitness than children from non-blended families, and blended only children experienced worse outcomes than only children with no half-siblings. Regardless of blended status, there was a negative relationship between birth order and fitness score. Model (3), using maternal cousin fixed effects, shows some further attenuation of the differences between nonblended and blended children but approximately the same pattern of effects between only children and those with siblings as model (2).

\section{Mortality results}

Figure 5 shows results for all-cause mortality at age 50 and over by sibling group size, birth order, and blended family status. Since we found no interaction effects between sibling group size, birth order, and sex, we are showing pooled models for men and 


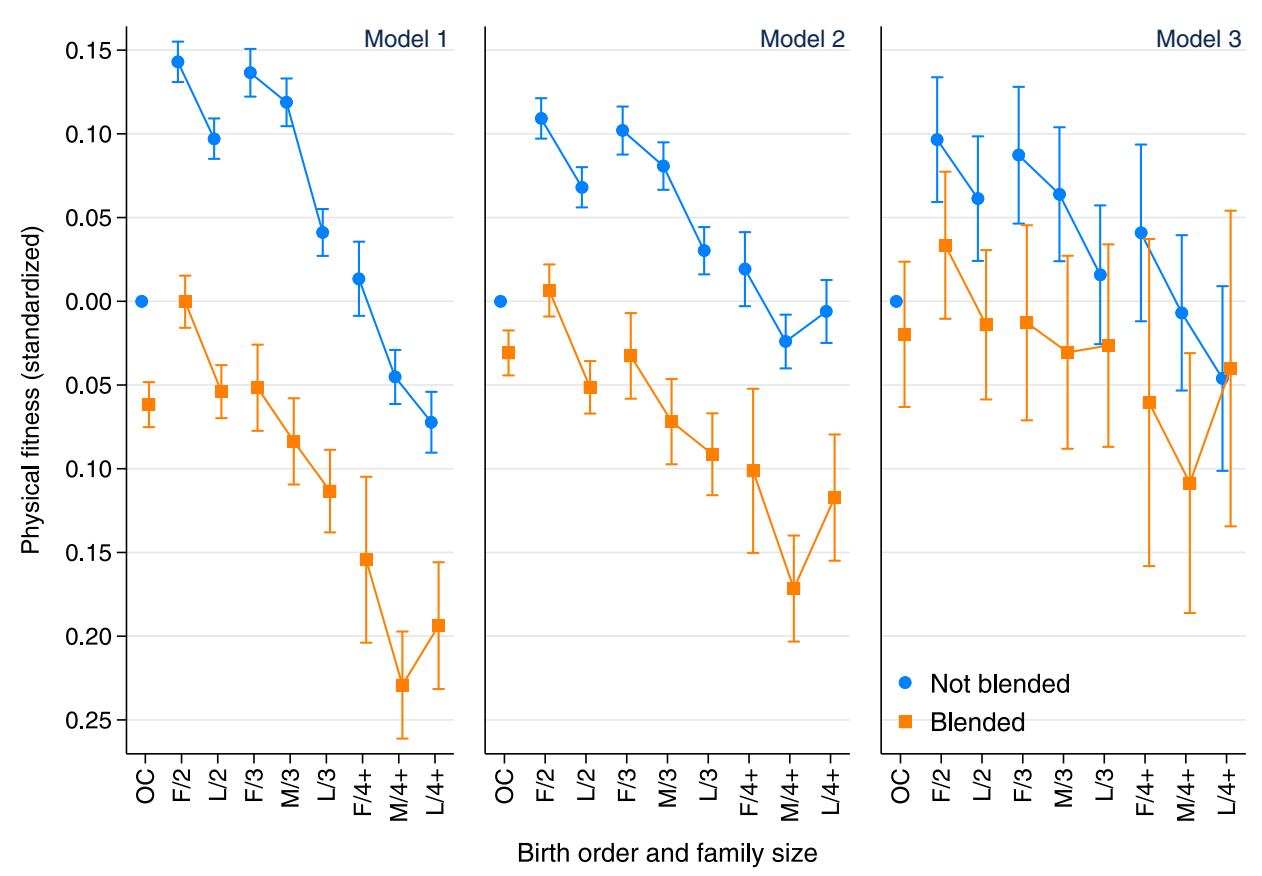

Figure 4 Results for standardized fitness scores among men aged 17-20, according to birth order, sibling group size, and blended family status: Swedish men born 1965-1975

Notes: Model (1) is adjusted for birth year only; model (2) also controls for parental characteristics. Model (3) is run on a subsample and includes maternal cousin fixed effects. Non-blended only children (OC) are the reference category. The remaining eight birth order and sibling group category labels indicate birth order (First, F; Middle, M; and Last, L) and sibling group size. For example, a firstborn child from a three-child sibling group is labelled F/3.

Source: As for Figure 1.

women. Model (1) shows estimates adjusted for birth year and sex, and model (2) additionally adjusts for parental characteristics: age, education, and socioeconomic status, as well as parental death before age 50. Model (3) additionally adjusts for life course characteristics of the index person, including socio-economic status (measured in 1990) and the following characteristics measured at age 50: marital status, educational attainment, and parity.

On comparing non-blended sibling groups with one another, we can see that the mortality hazard was highest among only children. Non-blended children with one or two siblings, and first and middleborn children with three or more siblings experienced significantly lower mortality (model (1)), and this effect persisted after controlling for parental characteristics (model (2)). After adjustment for life course factors (model (3)), the gap between only children and other sibling groups was reduced, suggesting that some of the negative influence was mediated through family history and socio-economic factors. As in earlier analyses, mortality outcomes were significantly worse for blended only children than non-blended only children. However, this disparity reduced substantially after controlling for life course factors in model (3). In fact, in all models, for nearly all sibling groups, children from blended families showed higher mortality than those from non-blended groups, but this disadvantage reduced after adjustment for life course factors, suggesting that this negative effect was mediated by poorer life course outcomes.

\section{Robustness checks}

As an additional robustness check, for all outcomes from conscription data we fitted identical models using paternal cousin fixed effects (for cousins sharing the same paternal grandmother), and these showed no substantial differences from those obtained when looking at maternal cousins. For the mortality models, we fitted the same models but started the mortality follow-up in 1990, rather than at age 50, and found broadly the same pattern of effects.

We also investigated the effect of using a slightly different specification of sibship size and halfsibling status, by classifying children into family size groups based on maternal fertility only (see Figures S1-S4 in the supplementary material). This means that an only child would be classed as blended only if the father has had a child with 


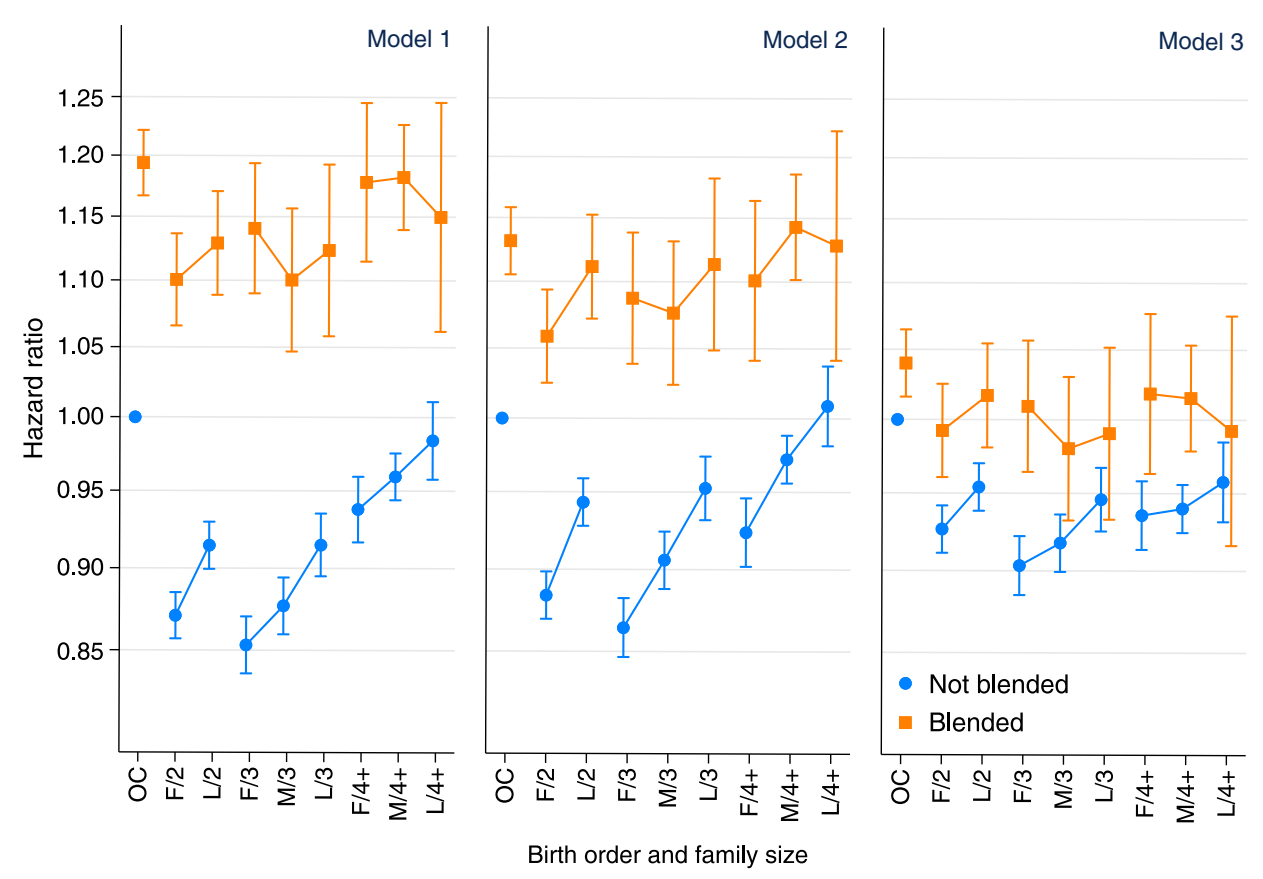

Figure 5 Results for all-cause mortality at age 50+, according to birth order, sibling group size, and blended family status: Swedish men and women born 1940-60, mortality 1990-2017

Notes: Model (1) is adjusted for birth year and sex; model (2) also controls for parental characteristics. Model (3) adjusts in addition for the index person's life course characteristics at age 50 . Non-blended only children (OC) are the reference category. The remaining eight birth order and sibling group category labels indicate birth order (First, F; Middle, M; and Last, L) and sibling group size. For example, a firstborn child from a three-child sibling group is labelled F/3.

Source: Authors' calculations from Swedish mortality register data.

another partner; children with half-siblings from the mother's side would be classified according to their sibship size based on maternal fertility. Overall, the pattern of effects was similar to those seen in the main results, with the exception that the contrast between non-blended and blended only children was attenuated in some cases to non-significance. An explanation for this could be that in this alternative specification, the only children with half-siblings due to maternal fertility contribute to the estimates in higher sibling size groups, rather than contributing to the difference between non-blended and blended only children.

\section{Discussion}

This paper is the first to our knowledge to investigate the health of only children relative to children raised in multi-child sibling groups, using high-quality, large-scale administrative data on a range of objectively measured health outcomes. Our first aim was to assess the extent of any health disadvantage among only children, relative to those in other sibling constellations. Our unadjusted analyses suggest that in Sweden non-blended only children are likely to be shorter, are more likely to suffer from overweight/obesity, and are more likely to exhibit lower levels of physical fitness in late adolescence compared with children from non-blended, two- and three-child families. However, only children show similar outcomes to those from nonblended, four-child families, with the exception of overweight/obesity and height. On the whole, only children, regardless of half-siblings, enjoy better health in late adolescence than children from larger, blended families. The mortality analyses also show that non-blended only children experience higher death rates in early old age than children with full biological siblings but do better than children with half-siblings. Overall, only children with halfsiblings experience consistently worse health outcomes than only children without half-siblings. Our study also highlights the striking health disadvantage of only children relative to firstborns, which is in contrast to the literature on only children's intellectual and social development (Mancillas 2006; Falbo 2012). 
Our second aim was to understand whether these associations are explained by any parental selection or other life course factors. After adjusting for a range of parental and family characteristics, the pattern of associations is somewhat attenuated, suggesting that familial and social selection play a role. In cousin fixed effects estimates, which control for many unmeasured and invariant factors shared between maternal cousins, the pattern of effects is broadly similar, but differences between only children and others are further attenuated suggesting that shared familial environmental or genetic factors may contribute to health disparities, especially for height.

Given the increasing prevalence of only children in many high-income contexts, it is important to understand the extent to which our results reflect some kind of genuinely disadvantageous dimension of being raised in an only-child family or whether these patterns may be attributed to familial selection factors. It is likely that parents of only children are negatively selected in a context such as Sweden, where there is a strong two-child norm, leading to poorer outcomes for their offspring. Although we attempt to adjust for a wide range of parental characteristics, including controlling for unobserved factors in our fixed effects analyses, we cannot rule out residual confounding on parental characteristics. The adjustments for parental health are limited to the data available: solely premature parental death, which is an extreme and uncommon occurrence in contemporary Sweden. Other parental health factors, such as being overweight/obese and less physically fit, may prevent parity progression either directly or indirectly (Barclay and Kolk 2020) and affect offspring outcomes. Less healthy men are also over-represented among those who have five or more children (Barclay and Kolk 2020), which may explain part of the disadvantage of children raised in sibling groups with four or more children.

The finding that BMI tends to be higher among only children corroborates evidence from a range of contexts (Meller et al. 2018; Park and Cormier 2018). Such a consistent finding across countries with different levels of parental selection bias into only child status points to the possibility of mechanisms in addition to parental selectivity, and this deserves further attention, given the potential public health implications. It is unclear whether the mechanisms relate to birthweight, childhood growth patterns, diet, or physical activity and also whether interventions are possible to prevent excess risk. It is also unclear whether weight disparities persist into adulthood and influence cardiovascular health. If only children approximate patterns seen in firstborns, we might expect higher blood pressure and higher BMI into adulthood (Howe et al. 2014; Derraik et al. 2015). Further work is needed to establish whether the association between only children and BMI is changing over time and is contextually sensitive.

One of the strengths of this study over previous studies of only children is that with such a large sample and detailed birth register, we can distinguish between only children with and without half-siblings. This is important because one of the suggested negative selection factors influencing only child outcomes is parental disruption, and we might expect only children with half-siblings to be further disadvantaged. Our results confirm substantial health differences between only children with and without half-siblings in adolescence and in later life, underlining the importance of considering the complexity of the only child status. More generally, our results also highlight that children from blended families are persistently disadvantaged on health measures and that some of this could be explained by poorer family and socio-economic outcomes over the life course.

There are some limitations to this study. Data restrictions prevent us from comparing life course outcomes of the same cohorts at different life stages or comparing the same health outcome among different cohorts, and this must be borne in mind when reflecting on our findings as a whole. We cannot assume that the mortality sample experienced poorer health in adolescence. In addition, the proportions of only children were higher in the later cohorts, and we are unable to investigate whether increased social selection could be driving the poorer health results from conscription data, as suggested in another study (Choi and Monden 2017). It would be very useful in future to conduct studies on the same outcome over time, where social selection may have changed, or to extend our investigation to other non-health outcomes, such as educational, socio-economic and family factors, throughout the life course. The use of cousin fixed effects, while innovative, has its limitations. While first cousins are more similar than non-related sample members, they share only 12.5 per cent of their genetic material and grow up in different families. The sample for maternal cousin fixed effects is necessarily restricted to sample members with aunts/uncles and with data for the maternal grandmother. The fact that one child is an only child while their cousin is not could be due to 
differences in health or general preferences between their parents (who are siblings). We do adjust for some of these factors (such as parents' premature death, marital status, and education) but others, such as personality, we are unable to account for.

Despite these limitations, this study makes a significant contribution to the limited existing literature on only children's health by introducing conceptual and methodological innovations and by showing in Sweden a clear adolescent health and mortality disadvantage among only children that is not fully explained by parental selection factors. Replicating the current study on other dimensions of wellbeing (e.g. intellectual development) of only children in Sweden would contribute to elucidating the mechanisms behind this. As the subpopulation of only children is expected to continue rising, future work should build on and expand this study to analyse the later-life health outcomes of only children in different contexts and/or time periods.

\section{Notes and acknowledgements}

1 Katherine Keenan is based in the School of Geography and Sustainable Development, University of St Andrews. Kieron Barclay is based at the Max Planck Institute for Demographic Research; the Department of Sociology, Stockholm University; and the Swedish Collegium for Advanced Study. Alice Goisis is based at the Max Planck Institute for Demographic Research and the Centre for Longitudinal Studies, University College London.

2 Please direct all correspondence to Katherine Keenan, School of Geography and Sustainable Development, Irvine Building, North Street, St Andrews, KY16 8LD, UK; or by Email: katherine-keenan@st-andrews.ac.uk

3 This work was partially supported by the Carnegie Trust for the Universities of Scotland [RIG008234] awarded to Katherine Keenan and by the Economic and Social Research Council [grant number ES/S002103/1] to Alice Goisis. This work was also supported by the Swedish Research Council (Vetenskapsrådet) via the Swedish Initiative for Research on Microdata in the Social and Medical Sciences (SIMSAM), grant 340-2013-5164.

\section{ORCID}

Katherine Keenan (1) http://orcid.org/0000-0002-96701607

Kieron Barclay (1) http://orcid.org/0000-0002-51428467

Alice Goisis @ http://orcid.org/0000-0002-3038-0337

\section{References}

Adler, A. 1930. Problems of Neurosis. New York: Cosmopolitan Book Co.

Amato, P. R. and B. Keith. 1991. Parental divorce and the well-being of children: A meta-analysis, Psychological Bulletin 110(1): 26-46. doi:10.1037/0033-2909.110.1.26

Andersson, G. 1997. The impact of children on divorce risks of Swedish women, European Journal of Population 13: 109-145. doi:10.1023/A:1005803001129

Bagley, S., J. Salmon, and D. Crawford. 2006. Family structure and children's television viewing and physical activity, Medicine and Science in Sports and Exercise 38(5): 910-918. doi:10.1249/01.mss. 0000218132.68268.f4

Bailey, R. E., T. J. Hatton, and K. Inwood. 2016. Health, height, and the household at the turn of the twentieth century, Economic History Review 69(1): 35-53. doi:10.1111/ehr.12099

Baranowska-Rataj, A., K. Barclay, and M. Kolk. 2017. The effect of number of siblings on adult mortality: Evidence from Swedish registers for cohorts born between 1938 and 1972, Population Studies 71(1): 4363. doi:10.1080/00324728.2016.1260755

Barclay, K. 2014. The Long-term Impact of Birth Order on Health and Educational Attainment, Stockholm Studies in Sociology, New series 59. Available: http://www.divaportal.org/smash/get/diva2:760839/FULLTEXT01.pdf (accessed: 2 February 2021).

Barclay, K. 2015. A within-family analysis of birth order and intelligence using population conscription data on Swedish men, Intelligence 49: 134-143. doi:10.1016/J. INTELL.2014.12.007

Barclay, K., K. Keenan, E. Grundy, M. Kolk, and M. Myrskylä. 2016. Reproductive history and postreproductive mortality: A sibling comparison analysis using Swedish register data, Social Science \& Medicine 155: 82-92. doi:10.1016/j.socscimed.2016.02.043

Barclay, K. and M. Kolk. 2015. Birth order and mortality: A population-based cohort study, Demography 52(2): 613-639. doi:10.1007/s13524-015-0377-2

Barclay, K. and M. Kolk. 2020. The influence of health in early adulthood on male fertility, Population and Development Review 46(4): 757-785. doi:10.1111/padr. 12357

Barclay, K. and M. Myrskylä. 2014. Birth order and physical fitness in early adulthood: Evidence from Swedish military conscription data, Social Science \& Medicine 123: 141-148. doi:10.1016/J.SOCSCIMED.2014.11.007

Barclay, K. and M. Myrskylä. 2016. Advanced maternal age and offspring outcomes: Reproductive aging and counterbalancing period trends, Population and Development Review 42(1): 69-94. doi:10.1111/j.17284457.2016.00105.x 
Barclay, K., M. Myrskylä, P. Tynelius, D. Berglind, and F. Rasmussen. 2016. Birth order and hospitalization for alcohol and narcotics use in Sweden, Drug and Alcohol Dependence 167: 15-22. doi:10.1016/j.drugalcdep.2016. 06.029

Becker, G. S. and H. G. Lewis. 1973. On the interaction between the quantity and quality of children, Journal of Political Economy 81(2, Part 2): S279-S288. doi:10. 1086/260166

Black, S. E., P. J. Devereux, and K. G. Salvanes. 2016. Healthy(?), wealthy, and wise: Birth order and adult health, Economics and Human Biology 23: 27-45. doi:10.1016/j.ehb.2016.06.005

Blake, J. 1981. Family Size and the Quality of Children. Springer-Verlag. doi:10.2307/2060941

Blake, J. 1989. Number of siblings and educational attainment, Science 245(4913): 32-36. doi:10.1126/science. 2740913

Bobbitt-Zeher, D., D. B. Downey, and J. Merry. 2016. Number of siblings during childhood and the likelihood of divorce in adulthood, Journal of Family Issues 37 (15): 2075-2094. doi:10.1177/0192513X14560641

Bras, H., J. Kok, and K. Mandemakers. 2010. Sibship size and status attainment across contexts: Evidence from the Netherlands, 1840-1925, Demographic Research 23: 73-104. doi:10.4054/DemRes.2010.23.4

Cernerud, L. 1993. The association between height and some structural social variables: A study of 10-year-old children in Stockholm during 40 years, Annals of Human Biology 20(5): 469-476. doi:10.1080/03014469300002862

Chen, J. Q. and L. Goldsmith. 1991. Social and behavioral characteristics of Chinese only children: A review of research, Journal of Research in Childhood Education 5(2): 127-139. doi:10.1080/02568549109594810

Cheng, T. O. 2013. China's little emperors: Medical consequences of China's one-child policy, International Journal of Cardiology 168(6): 5121-5125. doi:10.1016/ j.ijcard.2013.08.074

Cherlin, A. J., P. L. Chase-Lansdale, and C. McRae. 1998. Effects of parental divorce on mental health throughout the life course, American Sociological Review 63 (2): 239. doi:10.2307/2657325

Choi, S. and C. Monden. 2017. Where It Matters to Be the Only One: School Performance Outcomes of Only-children across 31 Countries (SocArXiv Papers). doi:10. 31235/OSF.IO/KC6X5

Choi, S., R. Taiji, M. Chen, and C. Monden. 2020. Cohort trends in the association between sibship size and educational attainment in 26 low-fertility countries, Demography 57(3): 1035-1062. doi:10.1007/s13524020-00885-5

Cox, D. R. 1972. Regression models and life-tables, Journal of the Royal Statistical Society: Series B (Methodological) 34(2): 187-202. doi:10.1111/j.2517-6161.1972.tb00899.x
Datar, A. 2017. The more the heavier? Family size and childhood obesity in the U.S., Social Science \& Medicine 180: 143-151. doi:10.1016/j.socscimed.2017.03.035

de La Rochebrochard, E. and H. Joshi. 2013. Siblings and child development, Longitudinal and Life Course Studies 4(3): 276-287. doi:10.14301/llcs.v4i3.248

Derraik, J. G. B., F. Ahlsson, M. Lundgren, B. Jonsson, and W. S. Cutfield. 2015. First-borns have greater BMI and are more likely to be overweight or obese: A study of sibling pairs among 26812 Swedish women, Journal of Epidemiology and Community Health 70(1): 78-81. doi:10.1136/jech-2014-205368

Diekmann, A. and H. Engelhardt. 1999. The social inheritance of divorce: Effects of parent's family type in postwar Germany, American Sociological Review 64 (6): 783-793. doi:10.2307/2657402

Downey, D. B. 1995. When bigger is not better: Family size, parental resources, and children's educational performance, American Sociological Review 60(5): 746-761. doi:10.2307/2096320

Downey, D. B. 2001. Number of siblings and intellectual development: The resource dilution explanation, American Psychologist 56(6-7): 497-504. doi:10.1037/ 0003-066X.56.6-7.497

Dronkers, J. and J. Härkönen. 2008. The intergenerational transmission of divorce in cross-national perspective: Results from the Fertility and Family Surveys, Population Studies 62(3): 273-288. doi:10.1080/ 00324720802320475

Einiö, E., J. Nisén, and P. Martikainen. 2016. Number of children and later-life mortality among Finns born 1938-50, Population Studies 70(2): 217-238. doi:10. 1080/00324728.2016.1195506

Engeland, A., T. Bjørge, R. M. Selmer, and A. Tverdal. 2003. Height and body mass index in relation to total mortality, Epidemiology 14(3): 293-299. doi:10.1097/ 01.EDE.0000047889.30616.73

Erikson, R., J. H. Goldthorpe, and L. Portocarero. 1979. Intergenerational class mobility in three western European societies: England, France and Sweden, The British Journal of Sociology 30(4): 415. doi:10.2307/589632

Falbo, T. 2012. Only children: An updated review, The Journal of Individual Psychology 68(1): 38-49.

Falbo, T. and D. F. Polit. 1986. Quantitative review of the only child literature: Research evidence and theory development, Psychological Bulletin 100(2): 176-189. doi:10.1037/0033-2909.100.2.176

Falbo, T. and D. L. Poston. 1993. The academic, personality, and physical outcomes of only children in China, Child Development 64(1): 18-35. doi:10.1111/j.14678624.1993.tb02893.x

Fenton, N. 1928. The only child, The Pedagogical Seminary and Journal of Genetic Psychology 35(4): 546-556. doi:10.1080/08856559.1928.10532171 
Frejka, T., J. M. Hoem, and T. Sobotka. 2008. Childbearing Trends and Policies in Europe (Vol. 13). Rostock: Max Planck Institute for Demographic Research.

Frisco, M. L. and M. Weden. 2013. Early adult obesity and U.S. women's lifetime childbearing experiences, Journal of Marriage and Family 75(4): 920-932. doi:10.1111/ jomf.12049

Gee, E. M. 1992. Only children as adult women: Life course events and timing, Social Indicators Research 26(2): 183-197. doi:10.1007/BF00304398

Goisis, A., B. Özcan, and P. Van Kerm. 2019. Do children carry the weight of divorce?, Demography 56(3): 785 811. doi:10.1007/s13524-019-00784-4

Grundy, E. and Ø. Kravdal. 2007. Reproductive history and mortality in late middle age among Norwegian men and women, American Journal of Epidemiology 167(3): 271-279. doi:10.1093/aje/kwm295

Hallal, P. C., J. C. K. Wells, F. F. Reichert, L. Anselmi, and C. G. Victora. 2006. Early determinants of physical activity in adolescence: Prospective birth cohort study, British Medical Journal 332(7548): 1002-1005. doi:10. 1136/bmj.38776.434560.7C

Hatton, T. J. and R. M. Martin. 2009. The effects on stature of poverty, family size, and birth order: British children in the 1930s, Oxford Economic Papers 62(1): 157-184. doi:10.1093/oep/gpp034

Haugaard, L. K., T. A. Ajslev, E. Zimmermann, L. Ängquist, and T. I. A. A. Sørensen. 2013. Being an only or last-born child increases later risk of obesity, PLoS ONE 8(2): e56357. doi:10.1371/journal.pone. 0056357

Homan, G. F., M. Davies, and R. Norman. 2007. The impact of lifestyle factors on reproductive performance in the general population and those undergoing infertility treatment: A review, Human Reproduction Update 13(3): 209-223. doi:10.1093/humupd/dml056

Howe, L. D., P. C. Hallal, A. Matijasevich, J. C. Wells, I. S. Santos, A. J. D. Barros, et al. 2014. The association of birth order with later body mass index and blood pressure: A comparison between prospective cohort studies from the United Kingdom and Brazil, International Journal of Obesity 38(7): 973-979. doi:10.1038/ijo.2013.189

Jelenkovic, A., K. Silventoinen, P. Tynelius, M. Myrskylä, and F. Rasmussen. 2013. Association of birth order with cardiovascular disease risk factors in young adulthood: A study of one million Swedish men, PLOS ONE 8(5): e63361. doi:10.1371/journal.pone.0063361

Kolk, M. 2014. Multigenerational transmission of family size in contemporary Sweden, Population Studies 68 (1): 111-129. doi:10.1080/00324728.2013.819112

Lappegård, T. and E. Thomson. 2018. Intergenerational transmission of multipartner fertility, Demography 55 (6): 2205-2228. doi:10.1007/s13524-018-0727-y
Lawson, D. W. and R. Mace. 2011. Parental investment and the optimization of human family size, Philosophical Transactions of the Royal Society B: Biological Sciences 366(1563): 333-343. doi:10.1098/rstb.2010.0297

Lesthaeghe, R. 2010. The unfolding story of the second demographic transition, Population and Development Review 36(2): 211-251. doi:10.1111/j.1728-4457.2010. 00328.x

Li, M., H. Xue, W. Wang, M. Wen, and Y. Wang. 2017. Increased obesity risks for being an only child in China: Findings from a nationally representative study of 19,487 children, Public Health 153: 44-51. doi:10. 1016/J.PUHE.2017.07.002

Mancillas, A. 2006. Challenging the stereotypes about only children: A review of the literature and implications for practice, Journal of Counseling and Development 84(3). doi:10.1002/j.1556-6678.2006.tb00405.x

McLanahan, S., L. Tach, and D. Schneider. 2013. The causal effects of father absence, Annual Review of Sociology 39(1): 399-427. doi:10.1146/annurev-soc071312-145704

Meller, F. O., C. L. de Mola, M. C. F. Assunção, A. A. Schäfer, D. L. Dahly, and F. C. Barros. 2018. Birth order and number of siblings and their association with overweight and obesity: A systematic review and meta-analysis, Nutrition Reviews 76(2): 117-124. doi:10.1093/nutrit/nux060

Min, J., H. Xue, V. H. C. Wang, M. Li, and Y. Wang. 2017. Are single children more likely to be overweight or obese than those with siblings? The influence of China's one-child policy on childhood obesity, Preventive Medicine 103: 8-13. doi:10.1016/J.YPMED. 2017.07.018

Monteiro, P. O. A. and C. G. Victora. 2005. Rapid growth in infancy and childhood and obesity in later life-A systematic review, Obesity Reviews 6(2): 143-154. doi:10.1111/j.1467-789X.2005.00183.x

Mosli, R. H., A. L. Miller, K. E. Peterson, N. Kaciroti, K. Rosenblum, A. Baylin, and J. C. Lumeng. 2016. Birth order and sibship composition as predictors of overweight or obesity among low-income 4- to 8-yearold children, Pediatric Obesity 11(1): 40-46. doi:10. 1111/IJPO.12018

Mosli, Rana H., J. C. Lumeng, N. Kaciroti, K. E. Peterson, K. Rosenblum, A. Baylin, and A. L. Miller. 2015. Higher weight status of only and last-born children. Maternal feeding and child eating behaviors as underlying processes among 4-8 year olds, Appetite 92: 167172. doi:10.1016/J.APPET.2015.05.021

Myrskylä, M., I. T. Elo, I. V. Kohler, and P. Martikainen. 2014. The association between advanced maternal and paternal ages and increased adult mortality is explained by early parental loss, Social Science \& Medicine 119: 215-223. doi:10.1016/J.SOCSCIMED.2014.06.008 
Myrskylä, M., K. Silventoinen, A. Jelenkovic, P. Tynelius, and F. Rasmussen. 2013. The association between height and birth order: Evidence from 652518 Swedish men, Journal of Epidemiology and Community Health 67(7): 571-577. doi:10.1136/jech-2012-202296

Öberg, S. 2015. Sibship size and height before, during, and after the fertility decline: A test of the resource dilution hypothesis, Demographic Research 32(1): 29-74. doi:10. 4054/DemRes.2015.32.2

Öberg, S. 2017. Too many is not enough: Studying how children are affected by their number of siblings and resource dilution in families, The History of the Family 22(2-3): 157-174. doi:10.1080/1081602X.2017.1302890

Ong, K. K. L., M. L. Ahmed, D. B. Dunger, P. M. Emmett, and M. A. Preece. 2000. Association between postnatal catch-up growth and obesity in childhood: Prospective cohort study, British Medical Journal 320(7240): 967971. doi:10.1136/bmj.320.7240.967

Park, S. H. and E. Cormier. 2018. Influence of siblings on child health behaviors and obesity: A systematic review, Journal of Child and Family Studies 27(7): 2069-2081. doi:10.1007/s10826-018-1049-9

Patton, J. F., J. A. Vogel, and R. P. Mello. 1982. Evaluation of a maximal predictive cycle ergometer test of aerobic power, European Journal of Applied Physiology and Occupational Physiology 49(1): 131-140. doi:10.1007/ BF00428971

Polit, D. F. and T. Falbo. 1987. Only children and personality development: A quantitative review, Journal of Marriage and the Family 49(2): 309. doi:10.2307/352302

Poston, D. L. and T. Falbo. 1990. Academic performance and personality traits of Chinese children: "Onlies" versus others, American Journal of Sociology 96(2): 433-451. doi:10.1086/229535

Präg, P., S. Choi, and C. Monden. 2020. The sibsize revolution in an international context: Declining social disparities in the number of siblings in 26 countries, Demographic Research 43: 461-500. doi:10.4054/ demres.2020.43.17

Ramlau-Hansen, C. H., A. M. Thulstrup, E. A. Nohr, J. P. Bonde, T. I. A. Sørensen, and J. Olsen. 2007. Subfecundity in overweight and obese couples, Human Reproduction 22(6): 1634-1637. doi:10.1093/ humrep/dem035

Riswick, T. and T. Engelen. 2018. Siblings and life transitions: Investigating the resource dilution hypothesis across historical contexts and outcomes, History of the Family 23(4). doi:10.1080/1081602X.2018.1532309

Rodrigues, L. P., R. F. Lima, A. F. Silva, F. M. Clemente, M. Camões, P. T. Nikolaidis, et al. 2020. Physical fitness and somatic characteristics of the only child, Frontiers in Pediatrics 8: 324. doi:10.3389/fped.2020.00324

Rostila, M. and J. M. Saarela. 2011. Time does not heal all wounds: Mortality following the death of a parent,
Journal of Marriage and Family 73(1): 236-249. doi:10.1111/j.1741-3737.2010.00801.x

Sandvik, L., J. Erikssen, E. Thaulow, G. Erikssen, R. Mundal, and K. Rodahl. 1993. Physical fitness as a predictor of mortality among healthy, middle-aged Norwegian men, New England Journal of Medicine 328(8): 533-537. doi:10.1056/NEJM199302253280803

Sear, R. 2006. Height and reproductive success, Human Nature 17(4): 405-418. doi:10.1007/s12110006-1003-1

Sheppard, P. and C. Monden. 2020. When does family size matter? Sibship size, socioeconomic status and education in England, Evolutionary Human Sciences 2. doi:10.1017/ehs.2020.54

Sisson, S. B., A. Sheffield-Morris, P. Spicer, K. Lora, and C. Latorre. 2014. Influence of family structure on obesogenic behaviors and placement of bedroom TVs of American children: National Survey of Children's Health 2007, Preventive Medicine 61: 48-53. doi:10. 1016/j.ypmed.2014.01.010

Statistika Centralbyråns. 2017. Multi-generation Register 2016: A Description of Contents and Quality. Stockholm, Sweden. Available: https://www.scb.se/contentassets/ 95935956ea2b4fa9bcaab51afa259981/ov9999_2016a01_ br_be96br1702eng.pdf (accessed 5 June 2019).

Stock, J. H. and M. W. Watson. 2008. Heteroskedasticityrobust standard errors for fixed effects panel data regression, Econometrica 76(1): 155-174. doi:10.1111/ j.0012-9682.2008.00821.x

Stradford, L., F. van Poppel, and L. H. Lumey. 2017. Can resource dilution explain differences in height by birth order and family size? A study of 389,287 male recruits in twentieth-century Netherlands, History of the Family 22(2-3): 214-235. doi:10.1080/1081602X. 2016.1230510

Stulp, G. and L. Barrett. 2016. Evolutionary perspectives on human height variation, Biological Reviews 91(1): 206-234. doi:10.1111/brv.12165

Thomson, E. 2014. Family complexity in Europe, The ANNALS of the American Academy of Political and Social Science 654(1): 245-258. doi:10.1177/ 0002716214531384

Thomson E., Gray E., and Carlson M. J. 2020. Multipartner fertility in Europe and the United States, in Schoen R. (ed), Analyzing Contemporary Fertility: The Springer Series on Demographic Methods and Population Analysis (Vol. 51). Cham: Springer. doi:10. 1007/978-3-030-48519-1_8

Torssander, J. and R. Erikson. 2010. Stratification and mortality-A comparison of education, class, status, and income, European Sociological Review 26(4): 465-474. doi:10.1093/esr/jcp034

Turunen, J. 2014. Adolescent educational outcomes in blended families: Evidence from Swedish register 
data, Journal of Divorce \& Remarriage 55(7): 568-589. doi:10.1080/10502556.2014.950897

Wang, H., M. Sekine, X. Chen, H. Kanayama, T. Yamagami, and S. Kagamimori. 2007. Sib-size, birth order and risk of overweight in junior high school students in Japan: Results of the Toyama Birth Cohort Study, Preventive Medicine 44(1): 45-51. doi:10.1016/J. YPMED.2006.07.015

Weitoft, G. R., A. Hjern, B. Haglund, and M. Rosén. 2003. Mortality, severe morbidity, and injury in children living with single parents in Sweden: A population-based study, The Lancet 361(9354): 289-295. doi:10.1016/ S0140-6736(03)12324-0

Wells, J. C. K., P. C. Hallal, F. F. Reichert, S. C. Dumith, A. M. Menezes, and C. G. Victora. 2011. Associations of birth order with early growth and adolescent height, body composition, and blood pressure: Prospective birth cohort from Brazil, American Journal of Epidemiology 174(9): 1028-1035. doi:10. 1093/aje/kwr232 